REVIEW

\title{
Clinical genetic counselling for familial cancers requires reliable data on familial cancer risks and general action plans
}

\section{K Hemminki, C Eng}

J Med Genet 2004;41:801-807. doi: 10.1136/jmg.2004.022731

Familial cancer clustering, without obvious heritability, poses a major challenge for current cancer risk assessment and management. Reliable determination of familial risks for cancer is important for clinical genetic counselling, but medically verified data on familial risks for many malignancies have been limited. However, the nationwide Swedish Family-Cancer Database allows a reliable characterisation of familial risk for all major neoplasms. Even though alert genetic counsellors and certainly clinical cancer geneticists will consider familial cancer clustering in their purview, the standard medical referral systems, which have already been shown to be poor in capturing and referring families at high risk for heritable cancers, are unlikely to ascertain familial aggregations of other cancers that are not known to belong to an inherited cancer syndrome. The data will be helpful in implementing evidence based guidelines for helping the general medical system to ascertain and refer even familial cancer clusters to cancer genetics professionals.

See end of article for authors' affiliations

Correspondence to: Dr K Hemminki, Division of Molecular Genetic Epidemiology, German Cancer Research Center (DKFZ), Im Neuenheimer Feld 580, D-69120 Heidelberg, Germany;

k.hemminki@dkfz.de

Received 12 May 2004 Accepted for publication 10 June 2004 (see fig 1). A family history is a risk factor for which advice and management may bring both medical and psychosocial benefits.

In the present article, we will discuss familial risks of all common cancers and their implication for clinical practice. The source of the empirical data is the Swedish Family-Cancer Database (SFCD), a unique resource covering the whole Swedish population as families, and containing data on medically diagnosed cancers in this population. ${ }^{5}$ The available data show that familial risk is a characteristic of practically all cancers. For some cancers, it is the only or the largest known risk factor. Moreover, for most types of cancers, such as breast and colorectal cancers, which are manifested both in defined heritable syndromes and in undefined familial aggregations, the latter affects many more families than the former. Among all cancer risk assessment clinics specialising by single organ systems, there appear to be more high risk breast-ovarian cancer clinical practices than high risk colon cancer clinics. ${ }^{6}$ This may be due to the current lack of data; for many common cancers, including prostate, lung, and bladder cancers, and non-Hodgkin's lymphoma, familial clustering is documented, but the precise molecular genetic basis remains largely unknown.

In the present article, we focus on familial aggregations of cancers, currently without known or obvious genetic bases, for which clinical genetic counselling is difficult. Medical caregivers are known not to take good family histories and indeed, only an average of $30 \%$ of medical charts have any family history at all. ${ }^{8}$ One recent study noted that fewer than 2.5 minutes was given to any discussion of family history in the average community family practice setting. ${ }^{8}$ Even in a leading US academic comprehensive cancer centre with a clinical cancer genetics service, only $7 \%$ of patients at high risk of a clear inherited cancer syndrome are recognised and referred to a cancer genetics clinic. ${ }^{9}$ Thus, by extrapolation, familial clusters of cancers will be even less recognised and most such patients would not see a specialist genetic counsellor or cancer genetics professional, and these patients would follow pathway 1 in fig 1 . The availability of cancer genetics counselling varies extensively, both nationally and internationally. In fact, it is unclear whether, if all

Abbreviations: HNPCC, hereditary nonpolyposis colon cancer; SFCD, Swedish Family-Cancer Database; SIR, standardised incidence ratio 


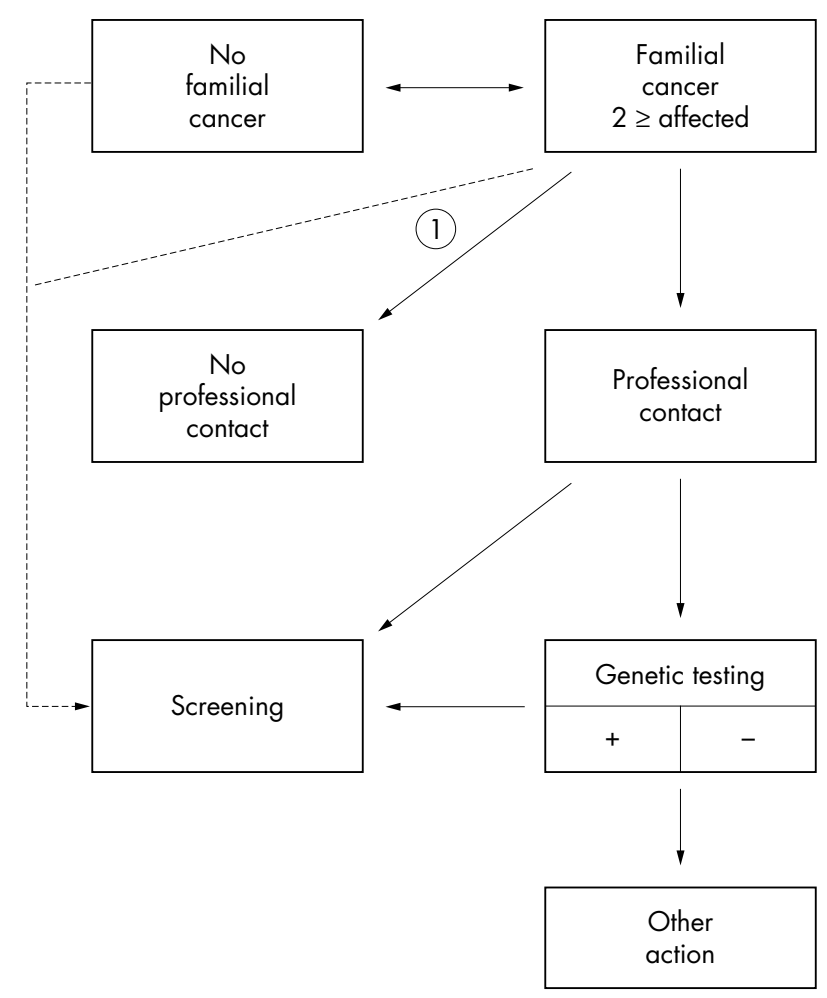

Figure 1 Management scheme for familial cancer. In an efficient clinical genetic counselling system, pathway 1 is relatively small, and different kinds of familial cancers receive attention.

familial clusters were referred to cancer genetics professionals, sufficient services would be available to meet these needs. We discuss heritable cancer syndromes or state of management for familial cancer below only insofar as they bear on familial risks in general. We want to assess the familial aggregation in cancers that are not commonly covered by the current referral criteria for cancer genetics consultations, reviewed recently by Hampel et al. ${ }^{2}$ We propose that sufficiently reliable data are available on familial risks on common cancers to draft guidelines and action plans for familial cancer at large. However, the formulation of such guidelines and management options requires input and expertise from many professional and interest groups and they remain beyond the scope of the present treatise. ${ }^{34}$

\section{HEREDITARY AND FAMILIAL CANCERS}

The magnitude of familial cancer risk is probably a continuum, ranging from high risk Mendelian conditions, for which practically all mutation carriers are affected, to low risk, perhaps polygenic conditions, for which a familial clustering can only be ascertained at a population level. ${ }^{10-12}$ These two extremes of the continuum are distinguished by the variable penetrance of the disease. Many high penetrant cancer syndromes have been recognised by examining pedigrees of cancer patients. ${ }^{13}$ Usually, a Mendelian pattern has been noted and the disease risk can be assessed for a mutation carrier reasonably accurately, similar to other Mendelian diseases. For many of the cancer syndromes, the underlying genes have been identified, and a gene test may be available and recommendable. ${ }^{3414}$ Clinical presentation and family history may be pathognomonic, diagnostic, or at least highly suggestive of a syndrome, and a cancer genetics professional may readily be able to recommend a gene test in the setting of genetic counselling. However, when syndrome defining features are lacking, as in the case of familial breast and colorectal cancer clusters, it is difficult to counsel based on molecular evidence, because these are sparse, and current recommendations are based on "clinical judgement" and expert opinion. ${ }^{15}{ }^{16}$ If we use familial clustering of breast and ovarian cancers, with no other features present, then a genetic differential diagnosis can be made, which includes hereditary breast-ovarian cancer syndrome and Lynch syndrome/hereditary nonpolyposis colon cancer (HNPCC) syndrome. ${ }^{3}$ However, such cluster presentations, in our experience, are rarely found to harbour germline mutations in the susceptibility genes for breast-ovarian cancer syndrome and Lynch syndrome. Recently, a germline CHK2 variant was reported to be associated with such families, ${ }^{17}$ but the attributable risk of cancer due to it is relatively low.

For low penetrance cancers, familial aggregation is present, but Mendelian patterns cannot be ascertained, genetic mechanisms have not been elucidated, and the only types of available risk estimates are derived from epidemiological studies. In many cancers, different levels of familial risk can be discerned without aetiological explanation. Typically, prostate cancer displays high and lower risk familial clustering, depending on the age of onset and the family relationships. ${ }^{18}{ }^{19}$ Clinical genetic counselling is currently based on these parameters. ${ }^{20-22}$ For some cancers, screening tests are available and may be recommendable in familial cases, irrespective of whether the genetic background of the disease in known (fig 1). ${ }^{22}{ }^{23}$ When the risk estimates are only derived from epidemiological studies, they may be difficult to translate to the individual based cancer genetics counselling. An extreme view is that epidemiological data are not useful for clinical counselling, which we will counter with the following example on breast cancer.

We would like to use two examples to illustrate the interphase of the Mendelian based cancer risk and the broader familial risks. For familial breast and ovarian cancer, various guidelines have been developed for offering genetic testing for BRCAI/2, and these consider age of onset and sex of the affected family members and the tumours affecting them. ${ }^{424} 25$ The proportion of all familial breast cancers due to mutations in the BRCAl/2 genes is about $20 \% .^{12}{ }^{26}$ This frequency is not inconsistent with results of selective population testing for BRCAl/2 mutations, which find some $30 \%$ of the targeted population positive ${ }^{16}$ However, the two clinically employed models for breast cancer risk assessment were devised before the identification of the highly penetrant breast cancer susceptibility genes. The Gail model predicts a woman's risk for breast cancer based on her individual risk factors, including a family history. ${ }^{27}$ This model was developed using data from a large follow up study. The Gail model has been evaluated in several settings and has been found to give reasonably accurate predictions of risk. ${ }^{28}$ Another model, the Claus model, was developed based on a case-control study, and has been useful for the estimation of heritable risks of breast cancer. ${ }^{29}$ However, because neither of these models takes family history, hormonal factors, and benign breast disease into account comprehensively, both models have been found to systematically underestimate risk of developing cancer in women who attended a cancer genetics clinic. ${ }^{30}$ A new model that does take all these factors into account, the Tyrer-Cuzick model, appears to be more consistently accurate. ${ }^{31}$ These are examples of how detailed epidemiological data provide relatively valid risk predictions in the absence of mutation analysis. Once mutational data become known, a further refinement of the risk assessment models must necessarily be made.

The second example is familial colorectal cancers, and the most prevalent underlying cancer syndrome, HNPCC, caused by germline mutations in mismatch repair genes and accounting for some $3 \%$ of all incident presentations of 
colorectal cancer in Finland..$^{32}$ The proportion of HNPCC among all colorectal cancer depends on the population and perhaps on the frequency of founder mutations. In Sweden, which lacks HNPCC founder mutations, an epidemiological estimate assumed $20-50 \%$ of familial colorectal cancers occurring in people before the age of 62 years to be HNPCC. ${ }^{33}$ In a clinical study, $1.2 \%$ of colorectal cancer patients were classified as HNPCC in Sweden. ${ }^{34}$ When clinical features vary in a single syndrome such as HNPCC, operational diagnostic criteria are made for one of two purposes: for research and for clinical use. There are several operational criteria for HNPCC. ${ }^{15}$ For example, the Amsterdam criteria were originally formulated to ascertain families for a gene hunt. For a gene hunt to be successful, such criteria necessarily have to be strict. Subsequently, clinicians have found that the Amsterdam criteria were too strict for clinical referral purposes, which led to the Amsterdam II criteria and the modified Amsterdam criteria. ${ }^{35}$ The relaxed Bethesda criteria were devised for purposes of offering testing for microsatellite instability (a cellular phenotype of mismatch repair deficiency). The frequency of finding germline mutations is dependent on the operational criteria and the mutation detection technology used. ${ }^{36}{ }^{37}$ Moreover, because of these limitations, when gene testing is negative in the face of a compelling family history, clinical follow up and screening is recommended. ${ }^{22}$ This has proven prudent, as subsequent studies have demonstrated that a substantial subset of these mutation negative HNPCC families harbour large germline deletions in the mismatch repair genes. ${ }^{38} 39$ We have estimated that the American Cancer Society Guidelines on familial colorectal cancer surveillance consider a familial risk of 2.2 to be an action level and recommend regular clinical screening. ${ }^{40}$ Although, admittedly, many types of data need to be considered for an action level for familial cancer clustering, it will be instructive to remember this risk of 2.2 when data on other cancers are discussed below.

\section{DATA SOURCES AND MEASURES FOR FAMILIAL RISK}

The above studies of Gail et $a l^{27}$ and Claus et $a l^{29}$ show how useful and reliable data from carefully conducted epidemiological studies may be under certain situations, even at times when new mechanistic data are becoming available. However, the reliability of the global literature on familial risks of other cancers does not match that of breast cancer. The basis for clinical genetic counselling and management of familial cancer needs to rest on a solid scientific fundament. Of the estimated 600 global papers reporting familial risks on cancer during the past two decades, about 500 are casecontrol studies. ${ }^{41}{ }^{42}$ The main problem in these studies is the possible inaccuracy of data on cancer in family members who had died a long time before the study. Most recent casecontrol studies have medically verified diagnosis of the cases, but only a few have verified the diagnoses of the relatives. Even many cohort studies lack verification of cancers in family members.

There is ample literature illustrating the problem of false reporting, the consequences of which are, however, largely ignored. False reporting appears to be low for breast cancer, intermediate for prostate cancer and melanoma, and highest for other internal neoplasms, for which the accuracy of reporting may be less than $50 \% .{ }^{43-49}$ This level of inaccuracy may cause severe bias to the derived risk estimates. Curiously, the direction of the bias is towards increased familial risks, with a probable indication that a patient with a certain type of cancer falsely reports the same cancer in a relative. ${ }^{40}{ }^{50-52}$ For example, excessive reported familial risks for gastric, oesophageal, and pancreatic cancers have not been confirmed is studies of medically verified cases of probands and family members ${ }^{51-53}$

Reliable familial risks can only be derived when all the component sources of data are reliable and of full coverage. The SFCD fulfils these criteria, except that even currently, a small proportion of the offspring population lacks a link to parents, as discussed elsewhere. ${ }^{40}$ The SFCD is a compilation of existing datasets, including the Multigeneration Register from Statistics Sweden, and cancer cases form the Swedish Cancer Registry (started in 1958). Parents of each offspring have been registered at the time of birth of the child. Thus it is possible to track "biological" parents and half siblings in spite of divorce and remarriage. The national personal identification code has been deleted from the SFCD, thus barring access to data on a specified individual. In the latest update of the SFCD, in 2002, over 10 million individuals and over 1 million tumours are included. With some 140 published papers in 5 years, the database has been the source of an overwhelming proportion of recent literature on familial risks in cancer. However, it is not the only source of registered data on familial cancers; the Utah Population Database, Danish datasets, British family records, and Icelandic genealogical records have also been successfully used. . $^{54-56}$

How is familial risk measured? The risk can be given as a standardised incidence ratio (SIR), which is the risk for cancer $X$ in offspring of parents diagnosed with cancer $X$ (that is, parents as probands); alternatively, the familial risk can be measured between siblings or any other familial relationships. SIR is calculated for offspring with an affected parent/sibling compared with those lacking an affected relative. Familial risks can also be given as relative risks (risk in those with an affected proband divided by risk in those lacking an affected proband). The SIRs presented later have been adjusted for age, socioeconomic status, and many other variables specified in the original papers. In general, with the exception of age, none of the variables available in the SFCD appear to confound familial risk. However, no data are available on tobacco smoking, which is likely to confound familial risks of lung cancer and perhaps of other tobacco related body sites.

In clinical practice, familial risks cannot usually be measured, thus surrogate measures, such as number of cases in a family, are used. This measure is sensitive to the family size, which has been an issue in, for example, the context of HNPCC. ${ }^{35}$ Age structures of the families are also crucially important when considering a disease of old age. Another issue is the definition of family: parent/ offspring, any first degree, second degree, or other relatives. For example, two first degree relatives with breast cancer would occur commonly by chance in any pedigree, whereas two sisters diagnosed before the age of 50 years would not.

Familial SIR is a relative measure, which shows how many times commoner that cancer is in those who have an affected family member, compared with those who have not, when age and some other factors are considered. For breast cancer, the most common familial cancer in the SFCD, an SIR of 2 would imply 900 extra cases among offspring (due to family history) in Sweden (population 9 million) in a 10 year follow up period. As comparison, an SIR of 4 for Hodgkin's disease would result in six additional cases in the same period; Hodgkin's disease is such a rare disease that the likelihood of being affected is very small, irrespective of a family history. Absolute risks, given as cumulative risks up to a certain age, may be more meaningful than relative risk in certain comparisons, and we give here cumulative risks according to the family history. All the rate calculations were based on the SFCD, the data of which are similar overall to those in the 
Swedish Cancer Registry, but differences may exist in some age specific data.

\section{EMPIRICAL DATA ON FAMILIAL RELATIVE AND ABSOLUTE RISKS FOR CANCER}

The 2002 update of the SFCD included 754165 first invasive cancers in parents (diagnosed at any age between 1961 and 2000 ) and 112216 in offspring (diagnosed between the ages of 0 and 68 years between 1991 and 2000). ${ }^{40}$ Familial risks were calculated for offspring when only a parent was affected by a concordant cancer, for siblings when parents were unaffected, and for offspring when a parent and a sibling were affected (table 1). When a parent was a proband, a total of 4934 familial cancers were found, with an overall SIR of 2.02. All the 24 site specific familial cancer risks were significantly increased. Hodgkin's disease showed the highest SIR, of 4.88, followed by testicular (4.26) and non-medullary thyroid cancer (3.26). Oesophageal cancer, ovarian cancer, and multiple myeloma had SIRs in excess of 3.00. Among common cancers the SIRs were increased for female breast cancer (1.84), and for prostate cancer (2.45) and colorectal adenocarcinomas (1.86), and the number of familial pairs ranged between 681 and 1779 for each.

Because of the age structure (offspring generation, maximally 68 years), fewer affected siblings than affected offspring-parent pairs were observed (1632 patients, table 1). Among siblings, 20 of the shown 21 sites had a significant effect, although the effect for pancreatic cancer was of borderline significance; the only exception was upper aerodigestive tract cancer, with no effect. Testicular cancer showed the highest SIR of 9.28, followed by Hodgkin's disease (5.94), kidney (4.74), prostate (4.46), and ovarian cancer (4.25). The third proband status, both a parent and a sibling affected, resulted in high SIR for many neoplasms. However, only 215 familial triplets were diagnosed for any of the cancers listed. Endocrine gland and ovarian tumours had the highest SIRs of over 30.00; even the SIR for stomach (12.66), endometrial (12.54) and squamous cell skin cancers (17.24) were very high.
Instead of relative risks, table 2 shows absolute risk for cancer in the offspring population up to age 68 years. Familial risks are considered for the three different proband statuses. Breast and prostate cancers showed the highest incidence rates for sporadic cases; the cumulative risks were 3.4 and $2.1 \%$, respectively. When a parent was affected with these cancers, the cumulative risks increased to 5.5 and $4.2 \%$, respectively. Among siblings, prostate cancer had the highest cumulative risk of $7.8 \%$. When both a sibling and a parent were probands, cumulative risks exceeded $10 \%$ for ovarian and prostate cancers and for melanoma.

Age is an important risk factor for cancer, and the cumulative risks will increase markedly at greater ages. The increase would affect relatively more sporadic cumulative risks, while the difference between these and the familial cumulative risks would be expected to become smaller.

\section{HERITABLE OR ENVIRONMENTAL FAMILIAL RISK}

Clinical counselling for familial cancer does not require that the causes of familial clustering are known, as was discussed above in the context of breast cancer risk assessment models. However, the counselling can be made more specific and effective if the causes are known. The first question is then whether the causes for familial aggregation are heritable or environmental. We have specifically tried to estimate the degree of environmental contribution to the familial risk by comparing cancer risks betweens spouses. Spouse concordance, which does not generally exceed a SIR of 1.4, can be noted only for cancers with known strong environmental risk factors: lung and genital cancers and early onset gastric cancers, pancreatic cancers, and melanoma. ${ }^{5758}$ Environmental factors are probably the main contributor to the familial aggregation of cervical, lung, and upper aerodigestive tract cancers, and a minor contributor to familial risks for melanoma and squamous cell skin cancer. ${ }^{59}{ }^{60}$ Thus, for most other sites, heritability is likely to be the main contributor.

Table 1 SIR for cancer in offspring when parents or siblings are probands

\begin{tabular}{|c|c|c|c|c|c|c|c|c|c|}
\hline \multirow[b]{2}{*}{ Cancer site } & \multicolumn{3}{|c|}{ Parental proband } & \multicolumn{3}{|c|}{ Sibling proband } & \multicolumn{3}{|c|}{ Both are probands } \\
\hline & 0 & SIR & $95 \% \mathrm{Cl}$ & 0 & SIR & $95 \% \mathrm{Cl}$ & 0 & SIR & $95 \% \mathrm{Cl}$ \\
\hline Upper aerodigestive tract & 39 & 1.72 & 1.22 to 2.35 & 6 & 1.41 & 0.51 to 3.10 & & & \\
\hline Oesophagus & 8 & 3.14 & 1.34 to 6.22 & & & & & & \\
\hline Stomach & 82 & 2.17 & 1.73 to 2.69 & 8 & 3.29 & 1.41 to 6.52 & 2 & 12.66 & 1.19 to 46.55 \\
\hline Colorectum* & 681 & 1.86 & 1.73 to 2.01 & 133 & 2.87 & 2.40 to 3.40 & 25 & 5.38 & 3.48 to 7.95 \\
\hline Liver & 37 & 1.66 & 1.17 to 2.28 & 2 & 1.05 & 0.10 to 3.85 & & & \\
\hline Pancreas & 46 & 1.87 & 1.37 to 2.49 & 6 & 2.75 & 0.99 to 6.04 & & & \\
\hline Lung & 365 & 2.09 & 1.88 to 2.32 & 92 & 3.13 & 2.53 to 3.84 & 8 & 5.06 & 2.16 to 10.02 \\
\hline Breast & 1779 & 1.84 & 1.76 to 1.93 & 826 & 2.03 & 1.89 to 2.17 & 98 & 3.27 & 2.66 to 3.99 \\
\hline Cervix & 39 & 1.82 & 1.29 to 2.49 & 13 & 2.10 & 1.11 to 3.59 & & & \\
\hline Endometrium & 83 & 2.48 & 1.97 to 3.07 & 20 & 2.05 & 1.25 to 3.17 & 3 & 12.54 & 2.36 to 37.11 \\
\hline Ovary & 97 & 3.15 & 2.56 to 3.85 & 38 & 4.25 & 3.01 to 5.84 & 6 & 31.64 & 11.39 to 69.33 \\
\hline Prostate & 922 & 2.45 & 2.30 to 2.62 & 189 & 4.46 & 3.85 to 5.15 & 55 & 8.62 & 6.49 to 11.23 \\
\hline Testis & 10 & 4.26 & 2.03 to 7.87 & 25 & 9.28 & 6.00 to 13.72 & & & \\
\hline Kidney & 64 & 1.87 & 1.44 to 2.38 & 26 & 4.74 & 3.09 to 6.95 & & & \\
\hline Urinary bladder & 117 & 1.75 & 1.45 to 2.10 & 21 & 2.02 & 1.25 to 3.10 & 3 & 8.16 & 1.54 to 24.16 \\
\hline Melanoma & 166 & 2.62 & 2.23 to 3.05 & 98 & 2.93 & 2.38 to 3.57 & 7 & 8.95 & 3.55 to 18.54 \\
\hline Skin, squamous cell & 77 & 2.52 & 1.99 to 3.15 & 12 & 3.63 & 1.87 to 6.37 & 2 & 17.24 & 1.63 to 63.41 \\
\hline Nervous system & 112 & 1.71 & 1.41 to 2.06 & 45 & 1.81 & 1.32 to 2.43 & 3 & 6.55 & 1.23 to 19.39 \\
\hline Thyroid gland, nonmedullary & 12 & 3.26 & 1.67 to 5.71 & 6 & 3.89 & 1.40 to 8.53 & & & \\
\hline Endocrine glands & 38 & 2.21 & 1.57 to 3.04 & 19 & 3.24 & 1.95 to 5.08 & 3 & 35.91 & 6.77 to 106.30 \\
\hline Non-Hodgkin's lymphoma & 74 & 1.82 & 1.43 to 2.28 & 24 & 2.25 & 1.44 to 3.35 & & & \\
\hline Hodgkin's disease & 8 & 4.88 & 2.08 to 9.66 & 5 & 5.94 & 1.87 to 13.96 & & & \\
\hline Myeloma & 23 & 3.33 & 2.11 to 5.00 & & & & & & \\
\hline Leukaemia & 55 & 1.85 & 1.39 to 2.41 & 18 & 3.02 & 1.79 to 4.78 & & & \\
\hline All & 4934 & 2.02 & 1.97 to 2.08 & 1632 & 2.45 & 2.33 to 2.57 & 215 & 5.00 & 4.35 to 5.72 \\
\hline
\end{tabular}


Table 2 Absolute risk for cancer in offspring when parents or siblings are probands

\begin{tabular}{|c|c|c|c|c|c|c|c|c|c|}
\hline & \multirow{2}{*}{$\begin{array}{l}\text { All cases in } \\
\text { offspring }\end{array}$} & \multicolumn{2}{|c|}{ Sporadic } & \multicolumn{2}{|c|}{$\begin{array}{l}\text { Parental } \\
\text { proband }\end{array}$} & \multicolumn{2}{|c|}{$\begin{array}{l}\text { Sibling } \\
\text { proband }\end{array}$} & \multicolumn{2}{|c|}{$\begin{array}{l}\text { Parent+sibling } \\
\text { proband }\end{array}$} \\
\hline & & $\overline{\mathbb{R}^{*}}$ & CR (\%)t & $\mathbf{I}^{*}$ & CR (\%) $\dagger$ & $\mathbb{R}^{*}$ & CR (\%)t & $\mathbf{I}^{*}$ & CR $(\%) \dagger$ \\
\hline Upper aerodigestive tract & 2104 & 4.5 & 0.4 & 6.0 & 0.5 & 12.1 & 1.1 & & \\
\hline Esophagus & 609 & 1.6 & 0.1 & 4.0 & 0.4 & & & & \\
\hline Stomach & 1492 & 3.5 & 0.3 & 8.3 & 0.7 & 9.5 & 0.9 & 59.2 & 5.7 \\
\hline Colorectum $\ddagger$ & 6774 & 17.5 & 1.6 & 30.7 & 2.6 & 49.8 & 4.3 & 85.2 & 6.9 \\
\hline Liver & 1423 & 3.6 & 0.3 & 4.1 & 0.3 & 2.6 & 0.2 & & \\
\hline Pancreas & 1536 & 3.9 & 0.3 & 7.9 & 0.7 & 8.6 & 0.7 & & \\
\hline Lung & 5493 & 13.7 & 1.2 & 26.8 & 2.3 & 42.9 & 3.7 & 56.7 & 4.5 \\
\hline Breast & 20923 & 41.1 & 3.4 & 68.8 & 5.5 & 88.2 & 7.1 & 124.9 & 9.6 \\
\hline Cervix & 2333 & 3.6 & 0.3 & 8.3 & 0.7 & 7.6 & 0.6 & & \\
\hline Endometrium & 2822 & 7.0 & 0.6 & 13.7 & 1.2 & 12.9 & 1.1 & 25.9 & 1.8 \\
\hline Ovary & 2969 & 5.8 & 0.5 & 15.2 & 1.2 & 40.6 & 2.9 & 151.1 & 11.1 \\
\hline Prostate & 5993 & 22.4 & 2.1 & 45.2 & 4.2 & 87.4 & 7.8 & 167.6 & 14.0 \\
\hline Testis & 1933 & 2.7 & 0.2 & 11.7 & 0.8 & 25.6 & 1.8 & & \\
\hline Kidney & 2307 & 5.4 & 0.5 & 12.6 & 1.0 & 35.4 & 2.6 & & \\
\hline Urinary bladder & 2987 & 7.8 & 0.7 & 13.8 & 1.2 & 7.6 & 0.6 & 39.0 & 3.4 \\
\hline Melanoma & 6529 & 11.9 & 1.0 & 37.1 & 3.1 & 39.5 & 3.1 & 226.3 & 18.4 \\
\hline Skin, squamous cell & 1898 & 4.8 & 0.4 & 10.1 & 0.9 & 11.4 & 0.9 & 69.8 & 6.3 \\
\hline Nervous system & 6137 & 11.0 & 0.9 & 22.7 & 1.8 & 24.9 & 2.0 & 74.9 & 6.3 \\
\hline $\begin{array}{l}\text { Thyroid gland, } \\
\text { nonmedullary }\end{array}$ & 1208 & 1.9 & 0.1 & 6.4 & 0.5 & 13.4 & 1.0 & & \\
\hline Endocrine glands & 2464 & 4.6 & 0.4 & 9.5 & 0.8 & 17.5 & 1.5 & 128.6 & 9.3 \\
\hline Non-Hodgkin's lymphoma & 3555 & 7.6 & 0.6 & 14.0 & 1.1 & 16.8 & 1.4 & & \\
\hline Hodgkin's disease & 1081 & 1.7 & 0.1 & 8.9 & 0.6 & 9.2 & 0.7 & & \\
\hline Myeloma & 901 & 2.2 & 0.2 & 5.8 & 0.5 & & & & \\
\hline Leukemia & 3200 & 6.5 & 0.5 & 9.2 & 0.8 & 16.5 & 1.3 & & \\
\hline
\end{tabular}

\section{CLINICAL COUNSELLING}

Advice given in clinical counselling aims to minimise cancer risks in the index case and his/her concerned family members. Table 1 shows a strong familial risk for lung cancer, but the primary recommendation to a family member of a lung cancer patient is to stop smoking. ${ }^{60}$ Similarly, clinical counselling on sexually transmitted cancers is concerned mainly with the avoidance of risk factors rather than with family history. In the case of melanoma and squamous cell skin cancer, counselling has to consider both; an affected sibling with one of these skin neoplasms signals a threefold risk, and if additionally a parent was affected, the risk is 10 fold or higher (table 1 ).

In fig 2, we summarise familial risks for all main cancers considering their prevalence. SIRs for offspring whose parents were affected (from table 1) are shown on the $y$ axis. On the $x$ axis, the width of the bars is proportional to the number of all familial cancers up to the age of 68 years. Breast cancer accounts for $36.1 \%$ of all familial cancers in the SFCD, and prostate cancer is second, with $18.7 \%$. Above the bars, the current protocols for clinical counselling are summarised. For the three most common cancers, advice and action plans are available, and ovarian and endometrial cancers will also be considered. For lung and cervical cancer, avoidance of risk factors should be offered, and for cervical cancer, effective screening is available. ${ }^{23}$ Similarly, avoidance and screening can be recommended for skin cancers. Advice on smoking cessation is in order for other tobacco related body sites. A careful family history or even personal features may give rise to recommendations for gene testing for von Hippel Lindau disease, multiple endocrine neoplasia, and some other known syndromes, ${ }^{23}{ }^{24}$ but for many common neoplasms, such as bladder cancer, stomach cancer, and non-Hodgkin's lymphoma, only surveillance can be recommended.

We pointed out earlier that the recommendations of the American Cancer Society Guidelines for Early Detection of Cancer on familial colorectal cancer consider a familial risk of 2.2 as an action level. Colorectal cancer is a relatively common cancer, implying that a familial risk of 2.2 will result in many cases. We will not argue that the risk of 2.2 should be universally applied as the basis for clinical action. However, in the absence of a more justified (evidence-based) action level, it offers a test case. A glance at table 1 shows that many of the familial cancers lacking established recommendations and action plans show familial risks in excess of 2.2, even though we show no age specific data. Although many types of data need to be considered for an action level of familial cancer, the data in table 1 show that familial SIRs exceed 2.2 for many cancers. These data would call for site specific or more uniform guidelines on a clinical counselling and a covering action plan for familial cancers in general. Indeed, in the USA, many academic centres that have comprehensive clinical cancer genetics programmes routinely place familial aggregations of cancers under a moderate risk category, calling for increased clinical surveillance. $^{2}$

Undoubtedly, the level of cancer genetics services including genetic counselling varies extensively and an alert counsellor pays attention to the number of affected family members with any kind of cancer as well as age of onset, ${ }^{2}$ yet bodies such as the American Cancer Society consider a family history as an indication for screening or surveillance only for cancers of the breast, prostate, colorectum, and endometrium for obvious reasons of cost effectiveness and the perceived impact on public health at large. These and similar guidelines may miss many other familial cancers of moderate risk. What is suggested by the familial cancer risks ascertained by population based databases is that the bulk of cancers may be included in this moderate risk category, which does demand increased clinical surveillance and screening. Given the projected volume, it is unclear if all existent cancer genetic services can cope. Even if cancer genetic services, including genetic counselling, are in place, there are two other important factors that must be considered. Firstly, the primary caregivers, who are at the front end of the referral chain, need to take a family history, to recognise familial cancer clustering, and to communicate the significance of this to the patient. ${ }^{61}$ Secondly, the patients need to understand the significance of an increased familial cancer risk so 


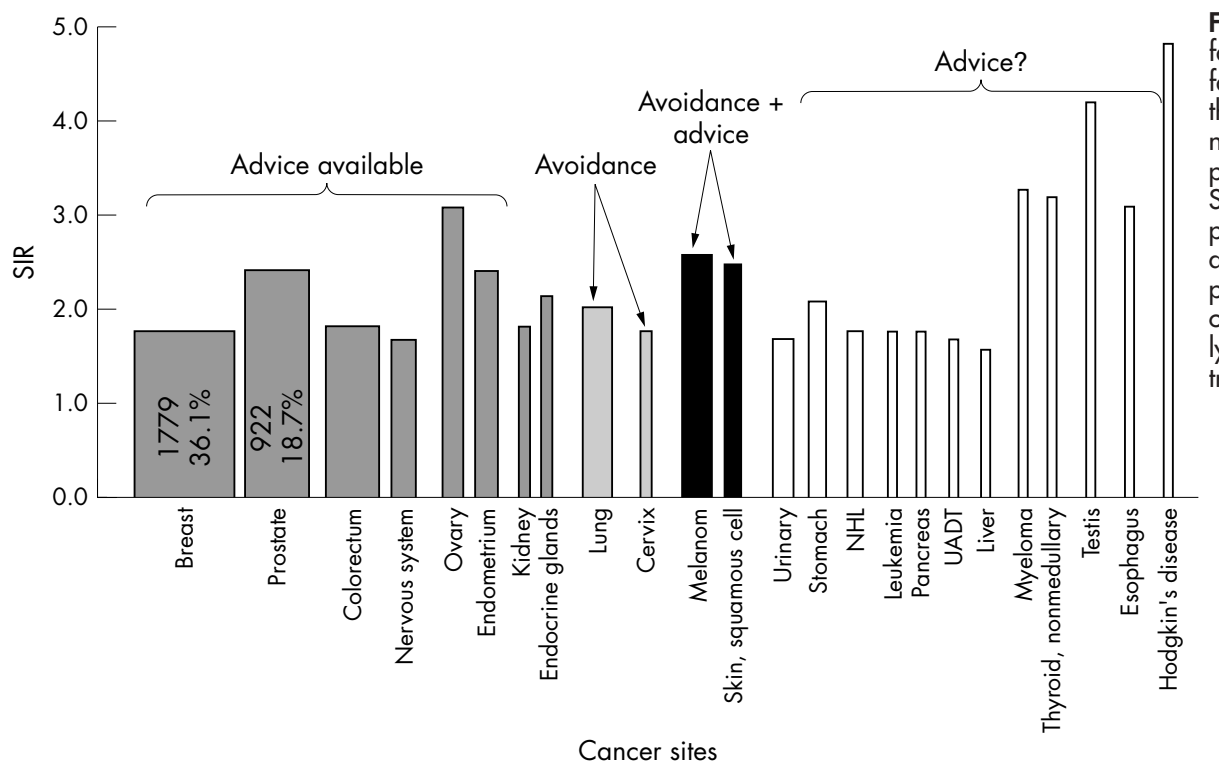

Figure 2 The relative prevalence of familial cancers as a proportion of all familial cancers in the SFCD, given as the width of the bars (the figures show numbers of familial cases and their percentage of all familial cases) and the SIRs for familial risk (y axis). In the top part of the figure, a comment is shown as to the availability of advice to patients seeking counselling for familial cancer. NHL, non-Hodgkin's lymphoma; UADT, upper aerodigestive tract.

Cancer sites

that an appointment with a cancer genetics professional is made and kept. Currently, at least in the USA, both recognition by primary caregivers and high risk communication with such patients are not optimised.9 ${ }^{91}$

\section{CONCLUSIONS}

The successes in early diagnosis and management of heritable cancers have shown evidence that inherited cancers are no longer inevitable. Although genetic testing has become an important method of premorbid diagnosis for at risk families of certain cancers, it covers a small proportion of all familial cancers and no objective tests are available for most cancers. Empirical risk estimates from epidemiological studies have proven to be useful for familial breast and prostate cancers, and we recommend that reliable risk estimates for other cancers also be seriously considered for routine clinical recommendations, as is already practised in several academic comprehensive clinical cancer genetics programmes. A familial, albeit low penetrant risk in a common cancer results in more cases in a given population than a high risk of a rare cancer, yet the familial risks are higher for some relatively rare neoplasms, such as testicular cancer and Hodgkin's disease, causing hardship in the affected families. Thus, implementation of a unified management plan for familial cancers at large will be a challenge firstly to the involved professionals and then to the other involved parties.

\section{ACKNOWLEDGEMENTS}

Xinjun Li provided the data to the tables and fig 2. The SFCD was created by linking registers maintained at Statistics Sweden and the Swedish Cancer Registry. K Hemminki has received grant support from Krebshilfe (Germany), the Swedish Cancer Society and the Konung Gustaf V's Jubilee Fund (Sweden). C Eng is the recipient of a Doris Duke Distinguished Clinical Scientist Award and is supported by the American Cancer Society, US Department of Defense, National Cancer Institute, National Institutes of Health, and the V Foundation. The Ohio State University Comprehensive Cancer Center is funded by P30CA16058 from the US National Cancer Institute.

\section{Authors' affiliations}

K Hemminki, Division of Molecular Genetic Epidemiology, German Cancer Research Center (DKFZ), Im Neuenheimer Feld 580, D-69120 Heidelberg, Germany; Department of Biosciences at Novum, Karolinska Institute, 14157 Huddinge, Sweden
C Eng, Clinical Cancer Genetics Program, Comprehensive Cancer Center, and Division of Human Genetics, Department of Internal Medicine, The Ohio State University, Columbus, OH 43210, USA; Cancer Research UK Human Cancer Genetics Research Group, University of Cambridge, Cambridge CB2 2XZ, UK

Conflict of interest: none declared

\section{REFERENCES}

1 International Agency for Research into Cancer. Cancer incidence in five continents. Lyon: IARC, 2002.

2 Hampel H, Sweet K, Westman J, Offit K, Eng C. Referral for cancer genetics consultation: a review and compilation of risk assessment criteria. J Med Genet 2004;41:81-91.

3 Eng C, Hampel H, de la Chapelle A. Genetic testing for cancer predisposition. Annu Rev Med 2001;52:371-400.

4 Petersen G, Codori A-M. Genetic testing for familial cancer. In: Vogelstein B, Kinzler K, eds. The genetic basis of human cancer, 2nd ed. New York: McGraw-Hill, 2002:643-56.

5 Hemminki K, Li X, Plna K, Granström C, Vaittinen P. The nation-wide Swedish Family-Cancer Database: updated structure and familial rates. Acta Oncol 2001:40:772-7.

6 Wonderling D, Hopwood P, Cull A, Douglas F, Watson M, Burn J, McPherson K. A descriptive study of UK cancer genetics services: an emerging clinical response to the new genetics. Br J Cancer 2001;85:166-70.

7 Medalie JH, Zyzanski SJ, Langa D, Stange KC. The family in family practice: is it a reality? J Fam Pract 1998;46:390-6.

8 Acheson LS, Wiesner GL, Zyzanski SJ, Goodwin MA, Stange KC. Family history-taking in community family practice: implications for genetic screening. Genet Med 2000;2:180-5.

9 Sweet KM, Bradley TL, Westman JA. Identification and referral of families at high risk for cancer susceptibility. J Clin Oncol 2002;20:528-37.

10 Peltonen L, McKusick V. Dissecting human diseases in the postgenomic era. Science 2001;291:1224-9.

11 Burghes AH, Vaessin HE, de la Chapelle A. Genetics. The land between Mendelian and multifactorial inheritance. Science 2001;293:2213-14.

12 Pharoah PD, Antoniou A, Bobrow M, Zimmern RL, Easton DF, Ponder BA. Polygenic susceptibility to breast cancer and implications for prevention. Nat Genet. 2002;31: 33-=6).

13 Vogelstein B, Kinzler K. The genetic basis of human cancer, 2nd ed. New York: McGraw-Hill, 2002.

14 Burke W. Genetic testing. New Engl J Med 2002;347:1867-75.

15 Vasen H, Mecklin J-P, Meera Khan P, Lynch H. The international collaborative group on hereditary non-polyposis colorectal cancer (ICG-HNPCC). Dis Colon Rectum 1991;34:424-5.

16 German Consortium for Hereditary Breast and Ovarian Cancer. Comprehensive analysis of 989 patients with breast or ovarian cancer provides $B R C A 1$ and $B R C A 2$ mutation profiles and frequencies for the German population. Int J Cancer 2002;97:472-80.

17 Meijers-Heijboer $\mathrm{H}$, van den Ouweland A, Klijn J, Wasielewski M, de Snoo A, Oldenburg R, Hollestelle A, Houben M, Crepin E, van Veghel-Plandsoen M, Elstrodt F, van Duijn C, Bartels C, Meijers C, Schutte M, McGuffog L, Thompson D, Easton D, Sodha N, Seal S, Barfoot R, Mangion J, ChangClaude J, Eccles D, Eeles R, Evans DG, Houlston R, Murday V, Narod S, Peretz T, Peto J, Phelan C, Zhang HX, Szabo C, Devilee P, Goldgar D, Futreal PA, Nathanson KL, Weber B, Rahman N, Stratton MR; CHEK2-Breast Cancer 
Consortium. Low-penetrance susceptibility to breast cancer due to CHEK2*1100delC in noncarriers of BRCA1 or BRCA2 mutations. Nat Genet 2002;31:55-9.

18 Narod S. Genetic epidemiology of prostate cancer. Biochim Biophys Acta 1999:1423:Fl-13.

19 Hemminki K, Czene K. Age specific and attributable risks of familial prostate carcinoma from the Family-Cancer Database. Cancer 2002;95:1346-53.

20 Walsh PC, Partin AW. Family history facilitates the early diagnosis of prostate carcinoma. Cancer 1997;80:1871-4.

21 Matikainen M, Pukkala E, Schleutker J, Tammela TU, Koivisto P, Sankila R, Kallioniemi O-P. Relatives of prostate cancer patients have an increased risk of prostate and stomach cancers: a population-based, cancer registry study in Finland. Cancer Causes Control 2001; 12:223-30.

22 Smith RA, Cokkinides V, von Eschenbach AC, Levin B, Cohen C, Runowicz CD, Sener S, Saslow D, Eyre HJ, American Cancer Society. American Cancer Society guidelines for the early detection of cancer. CA Cancer J Clin 2002;52:8-22

23 Boyle P. Current situation of screening for cancer. Ann Oncol 2002;13(Suppl 4):189-98.

24 American Society for Clinical Oncology. Policy statement update: Genetic testing for cancer susceptibility. J Clin Oncol 2003;21:2397-406.

25 National Comprehensive Cancer Network. Guidelines for detection prevention and risk of cancer, 2003. Available at: http://www.nccn.org.

26 Antoniou AC, Pharoah PD, McMullan G, Day NE, Ponder BA, Easton D. Evidence for further breast cancer susceptibility genes in addition to BRCA1 and BRCA2 in a population-based study. Genet Epidemiol 2001;21:1-18.

27 Gail MH, Brinton LA, Byar DP, Corle DK, Green SB, Schairer C, Mulvihill Jj. Projecting individualized probabilities of developing breast cancer for white females who are being examined annually. J Natl Cancer Inst 1989;81:1879-86.

28 Bondy ML, Newman LA. Breast cancer risk assessment models: applicability to African-American women. Cancer 2003;97(Suppl 1):230-5.

29 Claus EB, Risch NJ, Thompson WD. Age at onset as an indicator of familial risk of breast cancer. Am J Epidemiol 1990;131:961-72.

30 Amir E, Evans DG, Shenton A, Lalloo F, Moran A, Boggis C, Wilson M, Howell A. Evaluation of breast cancer risk assessment packages in the family history evaluation and screening programme. J Med Genet 2003;40:807-14.

31 Tyrer J, Duffy S, Cuzick J. A breast cancer prediction model incorporating familial and personal risk factors. Stat Med 2004;23:1111-30.

32 Lynch HT, de la Chapelle A. Hereditary colorectal cancer. N Engl J Med 2003;348:919-32.

33 Hemminki K, Li X. Familial colorectal adenocarcinoma and hereditary nonpolyposis colorectal cancer: a nation-wide epidemiological study from Sweden. Br J Cancer 2001;84:969-74.

34 Olsson L, Lindblom A. Family history of colorectal cancer in a Sweden county Fam Cancer 2003;2:87-93.

35 Potter J. Colorectal cancer: molecules and populations. J Natl Cancer Inst 1999:91:916-32.

36 Eng C, Brody LC, Wagner TM, Devilee P, Viig J, Szabo C, Tavtigian SV, Nathanson KL, Ostrander E, Frank TS; Steering Committee of the Breast Cancer Information Core (BIC) Consortium. Interpreting epidemiological research: blinded comparison of methods used to estimate the prevalence of inherited mutations in BRCA1. J Med Genet 2001;38:824-33.

37 Syngal S, Fox EA, Eng C, Kolodner RD, Garber JE. Sensitivity and specificity of clinical criteria for hereditary non-polyposis colorectal cancer associated mutations in MSH2 and MLH1. J Med Genet 2000;37:641-5

38 Yan H, Papadopoulos N, Marra G, Perrera C, Jiricny J, Boland CR, Lynch HT, Chadwick RB, de la Chapelle A, Berg K, Eshleman JR, Yuan W, Markowitz S Laken SJ, Lengauer C, Kinzler KW, Vogelstein B. Conversion of diploidy to haploidy. Nature 2000;403:723-4.

39 Wagner A, Barrows A, Wiinen JT, van der Klift H, Franken PF, Verkuiilen P, Nakagawa H, Geugien M, Jaghmohan-Changur S, Breukel C, MeijersHeijboer H, Morreau H, van Puijenbroek M, Burn J, Coronel S, Kinarski Y, Okimoto R, Watson P, Lynch JF, de la Chapelle A, Lynch HT, Fodde R. Molecular analysis of hereditary nonpolyposis colorectal cancer in the United
States: high mutation detection rate among clinically selected families and characterization of an American founder genomic deletion of the $\mathrm{MSH} 2$ gene. Am J Hum Genet 2003;72:1088-100.

40 Hemminki K, Li X, Czene K. Familial risk of cancer: data for clinical counseling and cancer genetics. Int J Cancer 2004; 108:109-14.

41 Collaborative Group of Hormonal Factors in Breast Cancer. Familial breast cancer: collaborative reanalysis of individual data from 52 epidemiological studies including 58209 women with breast cancer and 101986 women without the disease. Lancet 2001;358:1389-99.

42 Peto J, Houlston R. Genetics and the common cancers. Eur J Cancer 2001;37:S88-96

43 Fernandez E, La Vecchia C, D'Avanzo B, Negri E, Franceschi S. Family history and the risk of liver, gallbladder, and pancreatic cancer. Cancer Epidemiol Biomarkers Prev 1994:3:209-12.

44 Aitken JF, Youl P, Green A, MacLennan R, Martin NG. Accuracy of casereported family history of melanoma in Queensland, Australia. Melanoma Res 1996:6:313-17.

45 Kerber R, Slattery M. Comparison of self-reported and database-linked family history of cancer data in a case-control study. Am J Epidemiol 1997; 146:244-8

46 Gibbs M, Stanford JL, Mclndoe RA, Jarvik GP, Kolb S, Goode EL, Chakrabarti L, Schuster EF, Buckley VA, Miller EL, Brandzel S, Li S, Hood L, Ostrander EA. Evidence for a rare prostate cancer-susceptibility locus at chromosome 1p36. Am J Hum Genet 1999;64:776-87.

47 Glanz K, Grove J, Le Marchand L, Gotay C. Underreporting of family history of colon cancer: correlates and implications. Cancer Epidemiol Biomarkers Prev 1999:8:635-9.

48 Eerola H, Blomqvist C, Pukkala E, Pyrhonen S, Nevanlinna H. Familial breast cancer in southern Finland: how prevalent are breast cancer families and can we trust the family history reported by patients? Eur J Cancer 2000;36:1143-8.

49 King T, Tong L, Pack R, Spencer C, Amos C. Accuracy of family history of cancer as reported by men with prostate cancer. Urology 2002;59:546-50.

50 Carstensen B, Soll-Johanning H, Villadsen E, Söndergaard J, Lynge E. Familial aggregation of colorectal cancer in the general population. Int J Cancer 1996;68:428-35.

51 Hemminki K, Jiang Y. Familial and second gastric cancers: a nation wide epidemiologic study from Sweden. Cancer 2002;94:1157-65.

52 Hemminki K, Jiang Y. Familial and second esophageal cancers: a nationwide epidemiologic study from Sweden. Int J Cancer 2002;98:106-9.

53 Hemminki K, Li X. Familial and second primary pancreatic cancers: a nationwide epidemiologic study from Sweden. Int J Cancer 2003;103:525-30.

54 Goldgar DE, Easton DF, Cannon-Albright LA, Skolnick MH. Systematic population-based assessment of cancer risk in first-degree relatives of cancer probands. J Natl Cancer Inst 1994;86:1600-7.

55 Peto J, Easton D, Matthews F, Ford D, Swerdlow A. Cancer mortality in relatives of women with breast cancer: the OPCS study. Int J Cancer 1996:65:275-83.

56 Gudbjartsson T, Jonasdottir TJ, Thoroddsen A, Einarsson GV, Jonsdottir GM, Kristjansson K, Hardarson S, Magnusson K, Gulcher J, Stefansson K, Amundadottir LT. A population-based familial aggregation analysis indicates genetic contribution in a majority of renal cell carcinomas. Int $J$ Cancer 2002; 100:476-9.

57 Hemminki K, Dong C, Vaittinen P. Cancer risks to spouses and offspring in the Family-Cancer Database. Genet Epidemiol 2001;20:247-57.

58 Hemminki $\mathrm{K}$, Jiang $\mathrm{Y}$. Cancer risks among long-standing spouses. $\mathrm{Br} J \mathrm{Cancer}$ 2002;86:1737-40

59 Hemminki K, Dong C, Vaittinen P. Familial risks in cervix cancer: is there a hereditary component? Int J Cancer 1999;82:775-81.

60 Li X, Hemminki K. Familial and second lung cancers: a nation-wide epidemiologic study from Sweden. Lung Cancer 2003;39:255-63.

61 Sweet KM, Willis SK, Ashida S, Westman JA. Use of fear-appeal techniques in the design of tailored cancer risk communication messages: implications for healthcare providers. J Clin Oncol 2003;21:3375-6. 